\title{
๑๑®@ Política do reconhecimento: do reconhecimento à identidade em Taylor
}

\section{Caroline Domingues Silva da Costa*}

Resumo: Este artigo discute os conceitos de identidade e reconhecimento fundamentados na concepção de Charles Taylor a partir de sua obra Multiculturalismo (1998). Identidade possui uma relação direta com reconhecimento, uma vez que, para a identidade ser formada, parte dela é pela existência ou inexistência do reconhecimento. Taylor propõe uma política da diferença, visto que tal política possibilita o reconhecimento das diferenças existentes em cada indivíduo, o que proporciona uma possível sociedade multicultural não-hegemônica. Com isso, é possível observar neste artigo a elaboração do pensamento do autor acerca dos conceitos de identidade e reconhecimento. Também, é possível notar como estes conceitos viabilizam o reconhecimento de grupos minoritários que estão inseridos no corpo social. Para além disso, é analisado como que esses conceitos se tornam fundamentais para conseguir compreender a intersubjetividade de cada indivíduo e de como eles

\footnotetext{
* Mestranda em Sociologia pela Universidade Federal de Minas Gerais. Graduada em Filosofia pela Universidade Federal de São João del-Rei. E-mail: carolscosta21@gmail.com. ORCID: https://orcid.org/0000-0001-6719-4450
} 
são indissociáveis ao se pensar em uma luta por reconhecimento daqueles que tiveram o reconhecimento de suas identidades negadas. Palavras-chave: Autenticidade. Identidade. Intersubjetividade. Política da diferença. Reconhecimento.

\section{Politics of Recognition: from recognition to identity in Taylor}

Abstract: This paper discusses the concepts of identity and recognition based on Charles Taylor's conception from his book Multiculturalism (1998). Identity has a direct relationship with recognition, since, for identity to be formed, part of it is due to the existence or non-existence of recognition. Taylor proposes a politics of difference, since such politics make it possible the recognition of the differences that exist in each individual, which provides a possible non-hegemonic multicultural society. With this, it is possible to observe in this article the elaboration of the author's thought regarding the concepts of identity and recognition. Also, it is possible to notice how these concepts enable the recognition of minority groups that are inserted in the social body. Furthermore, it is analyzed how these concepts become essential in order to understand the intersubjectivity of each individual and how they are inseparable when we think about the fight for recognition of those who have their identities been denied to. 
Keywords: Authenticity. Identity. Intersubjectivity. Politics of Difference. Recognition.

\section{INTRODUÇÃO}

Charles Taylor possui uma visibilidade muito importante dentro do debate ético-político na contemporaneidade e é tido como um dos principais filósofos a abordar sobre o tema do reconhecimento. Taylor é autor de grandes obras atuais que abordam temas sobre multiculturalismo, ética, autenticidade e reconhecimento, assuntos que se tornaram importantes dentro desse debate político-filosófico.

Aprofundando em uma análise sobre a Modernidade, o autor consegue identificar as problemáticas geradas por ela e, então, debater sobre os seus assuntos. É notório a exigência de compreender o conceito de identidade na sociedade moderna. Taylor, inspirado em Hegel, buscou analisar a construção do self e como essa construção foi sendo moldada e reconfigurada desde a sociedade pré-moderna até a modernidade.

Em sua obra Multiculturalismo (1998), Taylor discute o desafio do multiculturalismo e, também, sobre como a política do reconhecimento é manifestada nas sociedades democráticas. Amy Gutmann, a autora do primeiro capítulo de seu livro, destaca que Taylor faz críticas a órgãos públicos que tratam indivíduos como 
iguais, não levando em consideração as suas identidades étnicas, religiosas, raciais ou sexuais (GUTMANN, 1998). Ao ignorar as multiplicidades dos indivíduos, as instituições públicas tomam como alvo-padrão apenas alguns tipos identidades únicas ao invés de pensarem em como alcançar mais diversidades.

Taylor ao falar sobre a sua teoria do reconhecimento, ele necessariamente perpassa pelos conceitos de identidade e autenticidade. Com isso, viu-se imprescindível retratar tais conceitos para enfim relacioná-los com o reconhecimento e a política da diferença. Tais ideais fazem parte do multiculturalismo de Taylor, que visa a inclusão de grupos minoritários dentro do corpo social. $\mathrm{O}$ autor destaca o termo grupo minoritário e chama a atenção reforçando que esses grupos são minoritários apenas na questão do reconhecimento, visto que em questão numérica, eles são em grande maioria.

Para além da necessidade do reconhecimento com um viés identitário, o reconhecimento também se torna fundamental para entender a construção do self. No decorrer deste artigo, será possível compreender em como a concepção de self está diretamente relacionada à questão do reconhecimento. Taylor ainda se preocupa em realçar a importância do reconhecimento intersubjetivo para assim conseguir trabalhar com o dilema existente entre a diferença e 
a igualdade. No mais, será abordado os conceitos de reconhecimento, identidade e autenticidade trazidos pelo autor.

$\mathrm{Na}$ primeira parte deste artigo será abordada a história da autenticidade a partir do século XVIII, quando esse conceito ganhou destaque na Modernidade. Em seguida, é trazida a relação dialética entre reconhecimento e identidade e será possível observar como os dois conceitos caminham juntos a fim de alcançar um autoconhecimento individual e coletivo, compreendendo também que o não-reconhecimento pode ser uma condição mobilizadora para aqueles que foram destituídos do mesmo para enfrentarem uma luta por reconhecimento. Por fim, será abordado sobre a política da diferença, um conceito trabalhado pelo autor que acentua a importância do reconhecimento das diferenças e como que isso é uma obrigação para o desenvolvimento de uma sociedade multicultural.

\section{A CULTURA DA AUTENTICIDADE}

A questão da autenticidade atingiu um espaço de discussão significativo na Modernidade. Anteriormente, na sociedade prémoderna, a identidade de um indivíduo era marcada a partir do pertencimento a uma comunidade ou uma polis. Não existia uma valorização do indivíduo, pelo contrário, os indivíduos só eram 
valorizados quando faziam parte de um grupo, eram valorizados pela sua identidade social. Somente na Modernidade é que o indivíduo passou a ser valorizado e a sua subjetividade recebeu uma atenção maior, abrindo mão da dimensão da eticidade desenvolvida anteriormente.

A sociedade moderna é marcada pela atenção que o indivíduo passa a receber e por explorar as subjetividades, adquirindo o direito da autonomia e da liberdade. Há a defesa de que, para estabelecer e formar identidades, o indivíduo basta em si mesmo. A construção da autenticidade e da identidade intersubjetiva é apoiada somente no indivíduo com ele mesmo, abandonando a relação de eticidade existente nas sociedades pré-modernas onde, a construção da identidade, dependia unicamente do pertencimento em grupos sociais.

Hegel, no entanto, destaca um problema na sociedade moderna quanto a isso e mostra um impasse. Para o autor, existe um avanço em trazer o indivíduo como centro e destacar as suas identidades, autonomia e autenticidade, parâmetros que, na sociedade prémoderna, eram deixados de lado. Contudo, Taylor, inspirado na filosofia hegeliana, destaca que o sujeito deseja ter sua identidade reconhecida e, esse sujeito autorreferencial discutido na sociedade moderna não é suficiente. Há, portanto, uma necessidade de recuperar a dimensão da eticidade, desenvolvida nas sociedades 
antigas para desenvolver o conceito de autenticidade atrelado ao reconhecimento. Com isso, Hegel (TAYLOR, 2005) recupera a dimensão da eticidade e reconfigura conforme os moldes da modernidade.

A ética da autenticidade é denominada como algo novo na sociedade moderna. Antes do século XVIII, as pessoas eram guiadas pelo sentimento de uma razão divina, no qual fazer o certo e o errado era uma questão de avaliar os castigos divinos que suas escolhas poderiam causar. A moralidade estava diretamente relacionada com uma voz interior que habitava dentro de cada um e guiava as suas escolhas, para o bem ou para o mal. Essa voz interior poderia ser chamada de Deus ou a Ideia do Bem (TAYLOR, 2011).

Logo no início do século XVIII, o ideal de autenticidade surgiu com o propósito de afirmar que os indivíduos possuem um senso moral, uma intuição do que é certo e errado. Desta forma, a autenticidade afirmava que a moralidade tem uma voz interna (TAYLOR, 2011) ressaltando o ideal do autêntico. A fonte com a qual nos conectamos está no fundo de nós mesmos e isso tem uma grande relevância para uma virada subjetiva da modernidade, onde nos colocam como seres com profundidade interior.

A autenticidade foi sendo desenvolvida de formas anteriores ao individualismo, como o que Descartes chamou de individualismo da racionalidade desengajada "no qual a exigência é de que cada pessoa 
pense de maneira autorresponsável por si mesma" (TAYLOR, 2011, p.35). A noção de autenticidade progrediu somente quando emergiu uma mudança da ênfase moral. Segundo a lógica da perspectiva original, a voz interior era importante porque ela nos dizia o que deveríamos fazer ou não. Assim, essa mudança surge a partir de quando a atenção que nós damos aos nossos sentimentos assume uma importância moral independente e fundamental.

Rousseau foi um dos filósofos mais importantes que cooperou para essa mudança da ênfase moral. Ele apresenta a questão da moralidade se referindo a uma voz interior dentro de cada pessoa. Essa voz interior, muitas vezes, é sufocada pelas paixões, desejos e pela dependência social. Logo, a nossa salvação moral só acontecerá quando conseguirmos recuperar o contato moral autêntico com nós mesmos. Rousseau também dialoga sobre uma outra perspectiva de liberdade, que Taylor denominou como liberdade autodeterminante. Tal liberdade afirma que o indivíduo só é livre quando decide por ele mesmo ao invés de ser moldado por influências externas (TAYLOR, 2011). Exige que o indivíduo rompa com tudo aquilo que foi imposto a ele, tomando decisões a partir dos seus ideais, sem ser moldado por algo externo ao mesmo, colocando a responsabilidade de suas escolhas em si.

Johann Gottfried von Herder foi um outro destaque importante, no qual o autor aprofundou e desenvolveu concepções acerca do 
ideal de autenticidade. Segundo o pensador, cada um de nós possui a sua própria maneira de ser humano, cada um possui sua própria “medida" (TAYLOR, 1998). Antes do século XVIII, a ideia de autenticidade nunca tinha sido considerada, visto que ninguém havia pensado que as diferenças existentes em cada pessoa pudessem ter uma importância moral. Se um indivíduo passa a viver conforme a medida de outra pessoa, ele perde a sua autenticidade e deixa de compreender o significado de ser humano. De acordo com Taylor (1998, p. 51):

É um ideal que aumenta consideravelmente a importância desse autocontato, ao introduzir o princípio da originalidade: cada uma das nossas vozes tem algo de único para nos dizer. Não só não deveria moldar a minha vida às exigências da realidade exterior, como nem sequer posso encontrar o modelo que me permite viver fora de mim. Só posso encontrá-lo dentro de mim. Ser verdadeiro para comigo mesmo significa ser verdadeiro para com a minha originalidade, que é algo que só eu posso descobrir e articular. Ao articulá-la, estou também a definir-me a mim mesmo. Estou a atualizar uma potencialidade que é própria de mim. É assim que se deve entender o ideal moderno de autenticidade e os objetivos de autorrealização e de autossatisfação que normalmente acolhem este ideal.

A concepção de moralidade foi introduzida na cultura da modernidade. Ela relaciona a importância moral com um contato único de cada indivíduo e de sua própria natureza interior que pode ser perdida. Por isso, é dada essa importância nesse autocontato ao falar do princípio da originalidade, pois cada uma de nossas vozes nos 
diz algo diferente onde cada um só pode encontrar um modelo a viver dentro de si. Assim, ser fiel a você mesmo é ser fiel à sua própria originalidade e, ao articular a sua originalidade, cada um consegue se definir e ter essa compreensão do ideal moderno de autorrealização e autossatisfação.

Ao pensar em autorrealização e autossatisfação, podemos debater acerca da teoria dialógica trazida por Taylor. O diálogo é uma das principais características da vida humana. É através dele que conseguimos nos comunicar e nos tornamos agentes humanos capazes de se relacionar com nós mesmos e com o outro, possibilitando uma troca e contribuindo para a formação da nossa identidade. E o diálogo com o outro nos permite a troca de linguagens gestuais, sonoras e visuais, no qual, a partir dessa troca, conseguimos uma autodefinição de nós mesmos. Dessa forma, Taylor classifica a gênese da mente humana como dialógica, uma vez que ela necessariamente precisa do diálogo para a sua formação e da interação com o outro, construindo a identidade através da diferença e da igualdade. (TAYLOR, 2011).

O termo "outros significantes" é trazido por Taylor para contemplar aqueles que fazem parte da vida de cada um e ajudam nessa troca a fim de auxiliar na formação da nossa identidade. Contudo, ele ressalta que, por mais que nossos familiares influenciem nessa formação, visto que eles estão conosco desde que 
nascemos, nós não devemos nos deixar ser moldados por eles. Os outros importantes nos auxiliam a descobrir como moldar nossa identidade e a ideia de quem somos, com isso Taylor $(2011$, p.43,44) assegura que:

Nunca poderemos nos libertar completamente daqueles
cujo amor e cuidado nos moldaram no começo da vida,
mas deveríamos lutar para nos definirmos sozinhos ao
grau mais pleno possível, vindo a entender da melhor
forma possível e, assim, ganhar algum controle sobre a
influência de nossos pais, e evitar cair ainda mais em
tais dependências. Precisaremos de relacionamentos
para satisfazer, mas não para definir a nós mesmos.

A identidade está diretamente relacionada com a cultura da autenticidade. Ao compreender o que significa a autodefinição e entender a sua própria originalidade, é possível compreender que a sua definição consiste em perceber as suas diferenças e semelhanças nos demais. A cultura da autenticidade é criticada com o argumento de que ela é focada apenas no self ${ }^{l}$, nos distanciando de relações com outras pessoas. Todavia, ao afirmar esse pensamento, desconsideram que a autenticidade propõe um novo modelo de sociedade, sugerindo como as pessoas devam viver juntas, para além de um individualismo

1 Self, segundo Taylor, está diretamente relacionada a concepção de uma identidade original. Segundo o autor, desenvolver a ideia do self é afirmar que o agente está se relacionando e projetando a sua vida. Reconhecer a identidade pessoal é reconhecer o seu lugar no mundo, a sua própria maneira de ser, o seu self original. Com isso, a construção do self acontece na medida em que o agente humano consegue se desenvolver no campo social, retomando a identidade a partir de uma concepção ética e política. 
moderno. Uma das facetas dessa cultura contempla a liberdade do indivíduo e as características formas de individualismo. Entretanto, o individualismo aqui citado está entrelaçado com um princípio moral e nos tenciona a como viver em sociedade, levando em consideração a nossa subjetividade sem excluir o coletivo.

$\mathrm{O}$ individualismo também possui uma especificidade baseada na ideia de que os indivíduos possuem o direito de se desenvolver a sua própria maneira de viver, a fim de alcançar a sua própria autorrealização. Essa concepção é relacionada ao individualismo da autorrealização, na qual o self é o centro. No entanto, é extremamente necessário ressaltar a noção de moral que existe por trás da autorrealização. A autenticidade é apenas uma faceta de um individualismo que precisa ser levada em consideração, visto que a autenticidade é um ideal válido, pois ela nos possibilita um autocontato e uma autodescoberta de nós mesmos, a fim de descobrir uma essência identitária. Taylor (2011, p.68) afirma que:

A noção de que cada um de nós possui uma maneira original de ser humano implica que devemos descobrir o que é sermos nós mesmos. Mas a descoberta não pode ser feita através da consulta de modelos preexistentes, por hipóteses. Por isso, pode ser feita apenas articulando-a de novo. Descobrimos o que temos que ser em nós ao nos tornarmos esse modo de vida, ao dar expressão em nosso discurso e ações ao que é original em nós. 
A autenticidade está para além do self, visto que esse ideal não propõe que o indivíduo sacrifique seus relacionamentos a fim de alcançar uma liberdade individual. Levar em consideração a sua essência é também uma forma de construir relacionamentos com os demais, através da linguagem com os outros importantes. Desclassificar e menosprezar tais sentimentos é deixar de lado uma parte da sua definição de ser. A autenticidade, neste sentindo, se difere de um egoísmo individual, onde todo o objetivo de sua autorrealização é centrado no self.

O ideal do autêntico se torna fundamental para conseguir contemplar a identidade individual de cada um. Somente com essa valorização do self é que se torna possível redescobrir a essência dos indivíduos e como eles se relacionam entre si através do diálogo. A troca de saberes, a partir da linguagem, possibilita uma nova forma de sociedade, uma vez que proporciona a inserção do reconhecimento na Modernidade. Somente pela busca de identidade é que a política do reconhecimento se torna possível em uma sociedade multicultural.

Portanto, o desenvolvimento do intersubjetivo é extremamente importante para enfim conseguir lidar com os impasses existentes entre a igualdade e a diferença. O pilar da luta por reconhecimento é constituído por uma luta intersubjetiva que depende diretamente dessa questão. É preciso, antes de qualquer coisa, entender o 
intersubjetivo para depois ampliar para as questões que movem lutas de reconhecimento. Afirmar que são apenas as questões de identidades e problemas centrados na autorrealização é ignorar a importância da intersubjetividade para uma luta por reconhecimento. Por isso se torna tão essencial discutir a questão da autenticidade com o intuito de entender que o intersubjetivo faz parte do reconhecimento no coletivo.

\section{RECONHECIMENTO E IDENTIDADE: UMA RELAÇÃO DIALÉTICA}

A discussão sobre a questão da identidade expandiu consideravelmente dentro da teoria política contemporânea. Discutir a definição de identidade dentro da modernidade passou a ter uma importância definitiva para debater acerca de um pertencimento dentro da sociedade em que o indivíduo está inserido. Essa busca pela identidade possibilita ao indivíduo entender a sua essência, particularidades e semelhanças com outros.

Segundo Taylor (TAYLOR, 1998), existem duas mudanças que se tornaram inevitáveis para essa discussão e preocupação sobre reconhecimento e identidade dentro da sociedade moderna. A primeira seria o desaparecimento das hierarquias sociais, o que constituiu a noção de honra. O termo honra é equivalente ao sentido que existia no antigo regime e estava relacionado as desigualdades 
entre os indivíduos. Para que uns pudessem ter honra era necessário que nem todos pudessem usufruir dela, uma vez que, se a honra fosse atribuída para todos os cidadãos, ela perderia o seu valor. Logo, a honra estava relacionada a uma posição social, dado que aqueles que possuíam ocupavam espaços sociais mais relevante, diferente dos demais, logo, ela era vista como um marcador social hierárquico.

Na modernidade, a dimensão da dignidade humana foi introduzida como essencial, o que levou a uma ruptura com o conceito de honra como um marcador social. A dignidade humana, assim como os direitos humanos, é vista a partir de um universalismo igualitário, o que seria comum e igual para todos. Do ponto de vista da teoria do reconhecimento, partir do pressuposto que todos possuem direitos iguais é ignorar as diferenças existentes entre as culturas, os povos e nos indivíduos. A necessidade do reconhecimento surge quando essas diferenças se tornam evidentes, exigindo que haja uma reconfiguração.

O problema do reconhecimento foi sendo moldado e ressignificado conforme a sua necessidade foi se ampliando. Com isso, ele passou a ter uma importância maior a partir de uma nova compreensão que surgiu no final do século XVIII, denominada como identidade individual. Essa identidade individual é definida como uma identidade particular que pertence apenas ao indivíduo, 
aquela que alguém consegue descobrir em si. Taylor (1998) utiliza a noção de autenticidade, trazida pela linguagem de Lionel Trilling, e a relaciona com a ideia de identidade particular. Assim, os conceitos de autenticidade e de identidade individualizada estão relacionados com a concepção de dar valor à singularidade, ressaltá-la, sendo verdadeiro com a sua própria maneira de ser.

De acordo com Taylor (1998), a identidade é definida como o conjunto de tudo que define a sua essência, sendo qualquer aspecto que possa definir alguém e como que essas características a tornam um ser humano. A identidade possui uma relação direta com a questão do reconhecimento dentro da igualdade, tanto que para a identidade ser formada, parte dela, é pela existência ou inexistência do reconhecimento, logo (MATTOS, 2006, p.57, 58):

A questão da identidade é respondida a partir da seguinte pergunta: quem sou eu? É interessante lembrar que esse tipo de questionamento só faz sentido para o homem moderno. Até o momento em que a ordem teísta detinha a capacidade de dar sentido para a vida, a questão da estrutura moral básica que dá sentido para a vida não era um problema individual. Nas condições modernas, se a resposta quanto a minha identidade é sempre individual e particular temos que reconhecer que só poderemos definir que coisas têm significado para nós dentro de um tipo de configuração moral específico. Se, levo, por outro lado, em conta o caráter universal envolvido em minha autodefinição, percebo que minha identidade é construída somente a partir das interlocuções com os outros. 
Com isso, a relação entre ambos é estabelecida a partir do diálogo, no qual os indivíduos definem suas identidades a partir da linguagem. Vale ressaltar que o diálogo, de acordo com Taylor (1998), vai além da linguagem verbal, logo, a linguagem é definida como toda e qualquer tipo de expressão humana. Podemos citar as linguagens da arte, do gesto, do amor e dentre outras. Todas essas linguagens nos ajudam a definir quem somos. A linguagem é ensinada as pessoas através de uma interação com outros, logo, a formação da mente humana é dialógica e não monológica. Com isso, identidade para Taylor (1998, p. 54):

É aquilo que nós somos, de onde nós provimos. Assim definido, é o ambiente no qual os nossos gostos, desejos, opiniões e aspirações fazem sentido. Se algumas das coisas a que eu dou mais valor estão ao meu alcance apenas por causa da pessoa que eu amo, então ela passa a fazer parte da minha identidade.

A partir do momento em que a descoberta da identidade é formada a partir diálogo, Taylor (1998) afirma que nós não nos dedicamos a ela sozinhos, mas sim, construindo-a coletivamente. Contudo, "precisamos das relações para nos realizarmos, mas não para nos definirmos" (TAYLOR, 1998, p.53). Assim, podemos atribuir uma importância significativa ao reconhecimento, pois ao gerar a identidade interiormente em relação ao diálogo com o outro, a própria identidade dependerá disso. 
Vale ressaltar que esse processo dialógico de uma dependência de descoberta da identidade não surgiu na era da autenticidade. Essa dependência sempre existiu. A identidade social dependia da sociedade. O diferencial é que o reconhecimento, nessa época, não era um problema para a sociedade antiga. $\mathrm{O}$ reconhecimento geral estava relacionado à identidade de origem social, baseando-se em causas sociais que não eram colocadas em pauta. A exigência e a luta pelo reconhecimento foi sendo cada vez mais exigida e a tendência é a continuidade, visto que as identidades não são estáticas e a necessidade do reconhecimento sempre irá existir.

A partir de Hegel é que a questão do reconhecimento começa a ser tratada de uma maneira mais significativa. $\mathrm{O}$ reconhecimento recebe sua devida importância e pode ser admitido de duas maneiras: no plano íntimo, onde a nossa identidade pode ser formada ou deformada conforme for a nossa relação com os demais; e no plano social, no qual temos uma política de um reconhecimento igualitário. Vale ressaltar que os dois planos sofreram influência do ideal de autenticidade - e o reconhecimento ganha um destaque importantíssimo nessa cultura que se formou a partir desse ideal.

No plano íntimo é possível observar que a identidade necessita de um reconhecimento concedido pelas pessoas que são importantes para nós, os outros importantes. Assim, na cultura da autenticidade, as relações são entendidas como pontos centrais da autodescoberta e 
da autoafirmação. Desta maneira, as relações de amor tomam um papel de extrema importância, uma vez que nelas podemos observar a identidade sendo constituída interiormente. O campo do amor é definido não somente por relações amorosas, mas, principalmente pelas primeiras influências que recebemos ao nascer, logo, no âmbito familiar. A construção do self se torna essencial no reconhecimento intersubjetivo dos indivíduos. Com isso, a necessidade da autenticidade é reforçada, dado que, é somente a partir da mesma é que os indivíduos conseguem alcançar a autorrealização.

O plano social é constituído pelas identidades que se formam através do diálogo aberto e que contribuem para tornar a política do reconhecimento mais central e marcante. $\mathrm{O}$ reconhecimento se faz necessário para uma sociedade democrática saudável, tanto que, o não-reconhecimento pode prejudicar pessoas e grupos sociais. A supremacia de um grupo sobre outro, tornando aquele grupo desprezível, tem um efeito de opressão, logo, a recusa de reconhecimento é uma forma de opressão.

O reconhecimento que foi negado ao indivíduo é identificado por Taylor como um reconhecimento errôneo. Taylor (1998) afirma que ao ter o reconhecimento negado, a opressão desses sujeitos acontece na medida em que os mesmos internalizam essa imagem negativa. Em uma mesma perspectiva, Axel Honneth (2003), ao 
abordar sobre o assunto do não-reconhecimento, classifica-o como desrespeito. De acordo com o autor, o não-reconhecimento é uma forma de desrespeito aos indivíduos e impede a autorrealização dos mesmos. Nas palavras de Honneth (2003, p.213):

pois, na autodescrição dos que se veem maltratados por outros, desempenham até hoje um papel dominante categorias morais que, como as de "ofensa" ou de "rebaixarnento", se referem a formas de desrespeito, ou seja, as formas do reconhecimento recusado. Conceitos negativos dessa espécie designam um comportamento que não representa uma injustiça só porque ele estorva os sujeitos em sua liberdade de ação ou lhes inflige danos; pelo contrário, visa-se àquele aspecto de um comportamento lesivo pelo qual as pessoas são feridas numa compreensão positiva de si mesmas, que elas adquiriram de maneira intersubjetiva.

Compreendendo que a identidade dos indivíduos é formada na intersubjetividade através do diálogo com os demais, essas situações de desrespeito podem agredir e oprimir os mesmos. Os indivíduos quando não alcançam esse reconhecimento que, segundo Taylor (1998) é um direito vital, eles se submetem a uma luta em busca de alcançar as relações intersubjetivas do reconhecimento. Com isso, Honneth (2003) afirma que toda luta por reconhecimento é iniciada a partir de uma experiência de desrespeito. As experiências negativas relacionadas ao não-reconhecimento podem ser convertidas em estímulos motivacionais para ir em busca do reconhecimento que foi negado. Em respeito a luta por reconhecimento, Mendonça $(2009$, p. 147) afirma que: 
Nas teorias de Honneth e Taylor, o reconhecimento é uma luta intersubjetiva. Isso tem uma série de implicações. Admitir que se trata de uma luta é assumir que o reconhecimento não pode ser concedido, alcançado ou doado. $\mathrm{O}$ reconhecimento não está restrito a fins específicos, nem é limitado a conquistas na esfera de direitos garantidos pelo Estado. Ele não é um prêmio final que liberta grupos oprimidos. A luta por reconhecimento pode ter muitas manifestações diferentes, na medida em que ela não é nada mais do que um processo permanente em que a sociedade reflexivamente se transforma e altera padrões de relação social.

A noção de identidade na Modernidade causou uma transformação no entendimento sobre identidade, originando, segundo Taylor (1998), uma política da diferença. Assim como a política de dignidade universal, a política da diferença também possui uma base universalista, dado que consiste no direito em que todos os indivíduos possuem o direito de serem reconhecidos. As duas políticas partem do princípio de que todos têm direitos e esses direitos precisam ser garantidos e assegurados. A diferença se encontra na perspectiva e no entendimento sobre o reconhecimento. Enquanto que na política de igual dignidade o reconhecimento está atrelado a uma noção de igualdade universal para todos, a política da diferença exige o reconhecimento de identidades únicas, ressaltando a autenticidade de cada indivíduo. Nas palavras de Taylor (1998, p. 62-63):

Os críticos do domínio europeu ou branco, tendo em conta que os europeus ou os brancos não só 
suprimiram, mas também não conseguiram valorizar as outras culturas, consideram estes juízos de valor depreciativos como sendo factualmente incorretos e também, de algum modo, moralmente errados. [...] Queixam-se do facto de o conjunto, supostamente neutro, de princípios que ignoram a diferença e que regem a política de igual dignidade ser, na verdade, um reflexo de uma cultura hegemónica. Se assim é, então só a minoria ou as culturas subjugadas são forçadas a alienarem-se. Consequentemente, a suposta sociedade justa e ignorante das diferenças é, não só inumana (porque subjuga identidades), mas também ela própria extremamente discriminatória, de uma maneira sutil e inconsciente.

Portanto, Taylor realça essa falha existente na política de igual dignidade. Mesmo que o respeito seja um dos pontos principais nesta política, ao não levar em consideração as diferenças existentes entre os grupos presentes dentro da sociedade, o respeito passa a não existir, uma vez que os mesmos precisam ser reconhecidos pelas suas especificidades, para não resultar em uma opressão e agressão a eles. É somente através do reconhecimento das diferenças que grupos minoritários passam a ter espaço no corpo social. Mendonça afirma que (2009, p.145):

Segundo Taylor (1994), o reconhecimento envolve, portanto, um misto de políticas universais e políticas da diferença. Para alcançar a possibilidade da autorrealização, as pessoas lutam, simultaneamente, por dignidade e para que as suas particularidades sejam reconhecidas. Fazem-no em esferas íntimas e públicas de interação social. Taylor sugere que, nessas lutas, a diferença profunda deve ser submetida a comparações de modo a promover fusões de horizontes, no sentido 
gadameriano do conceito. Isso depende da interação permanente com o outro.

Por fim, Taylor destaca que alguns aspectos da política atual impulsionam uma exigência de reconhecimento. A exigência seria por parte de grupos minoritários ou subalternos, precisando do reconhecimento para obter seu devido espaço no corpo social. Há, portanto, uma necessidade em definir a identidade de cada indivíduo e reconhecer grupos minoritários, que muitas vezes são massacrados por um grupo dominante. Sair de uma política universalista e adotar uma política de diferença é reconhecer as particularidades e reconhecer que cada um de nós é uma expressão autêntica de ser humano.

\section{A POLÍTICA DO RECONHECIMENTO E O RESPEITO ÀS DIFERENÇAS}

Foi dito anteriormente que a concepção de reconhecimento para Taylor está atrelada ao diálogo. O autor desenvolve uma teoria dialógica com um viés intersubjetivo, na qual toda a formação de sujeitos acontece a partir da interação com o outro e sua intersubjetividade é formada a partir do reconhecimento ou o nãoreconhecimento com os demais. O diálogo ocupa um papel importantíssimo na construção do eu, que pode tanto ser em uma esfera íntima, ao existir esse relacionamento com os indivíduos e com os outros importantes, quanto na esfera social, ou seja, na esfera 
pública a partir de uma política de reconhecimento igualitário, possibilitando que grupos usufruam de suas identidades reconhecidas.

Analisando a política do reconhecimento, é possível destacar que, anteriormente, na transição da sociedade pré-moderna para a moderna, surge uma política do universalismo. Nessa política é defendido a dignidade igual para todos os sujeitos. Somente a partir do desenvolvimento sobre concepções de identidade, indivíduo e reconhecimento é que surge na modernidade uma política da diferença. Nessa concepção, tal política não busca mais um universalismo de direitos iguais. Sua tese consiste na ideia de que "todas as pessoas devem ser reconhecidas pelas suas identidades únicas" (TAYLOR, 1998, p.58) dando o devido reconhecimento aos grupos e indivíduos, ressaltando a identidade particular de cada um.

Tanto na política do universalismo quanto na política da diferença, todos os indivíduos devem ter suas identidades reconhecidas. Contudo, existem divergências que devem ser mencionadas. A política do universalismo pretende oferecer os mesmos direitos a todos, sem necessariamente levar em consideração as peculiaridades existentes entre as identidades. Designar os mesmos direitos a todos é uma forma de exclusão, visto que os indivíduos possuem necessidades diferentes que devem ter uma atenção voltada a cada uma delas. 
O ideal da política de dignidade universal nega o ideal da autenticidade ao estabelecer direitos universais a partir de uma identidade da maioria como dominante. Estabelecer uma política que, na qual, exista um modelo a ser seguido para ser contemplado é ignorar a diversidade de identidades que há. A partir dessa perspectiva, emerge a política da diferença, sustentando o ideal de que todos possuem uma identidade única e individual que deve ser respeitada. O universal é aplicado de outra maneira, onde há o direito de todos serem reconhecidos a partir do ideal da autenticidade.

A política da diferença destaca as especificidades dos indivíduos ou de grupos. Com o intuito de proporcionar um reconhecimento ressaltando as diferenças que distingue dos demais, essa política torna-se ainda mais inclusiva, visto que se preocupa com o que chamamos de grupos minoritários. Taylor (1998, p.58, 59) afirma que "a ideia é de que é precisamente esse elemento distintivo que foi ignorado, distorcido, assimilado a uma identidade dominante ou majoritária. E essa assimilação é o pecado capital contra o ideal da autenticidade".

A política de dignidade igualitária não leva em consideração as diferenças existentes em todos os seres humanos, tornando assim direitos universais. $\mathrm{O}$ conceito de universalismo, ao tentar englobar diferentes culturas e denominá-las como iguais, visto que, em sua 
percepção, precisam de direitos iguais, comete sérios crimes de discriminação contra esses grupos. Não reconhecer os indivíduos pelas suas especificidades também é uma forma de violência. $\mathrm{Na}$ política da diferença, todos os cidadãos devem ser reconhecidos pelas suas singularidades e não de forma universal. Todos devem ser reconhecidos pelas suas identidades ímpares. Ressaltar a identidade individual de cada um é possibilitar uma maior forma de inclusão de reconhecimento dentro do corpo social. De acordo com Taylor (1998, p.59):

A política da diferença implica inúmeras denúncias de discriminação e recusa da cidadania de segunda categoria. É aqui que o princípio da igualdade universal coincide com a política de dignidade. Todavia, as exigências daquela dificilmente são assimiladas nesta, pois tal implica que reconheçamos a importância e o estatuto de algo que não é universalmente comum. Ou, dito de outra maneira, só reconhecemos aquilo que existe universalmente - todos possuem uma identidade -, aquilo que é peculiar a cada um. A exigência universal estimula um reconhecimento da especificidade.

Fica perceptível que uma das maiores disparidades entre a política de dignidade universal e a política da diferença é a de que a segunda leva em consideração as diferenças existentes e a partir delas cria uma política distinta, com base nessas disparidades. Enquanto a política de dignidade universal visa à igualdade e o fim da discriminação, ignorando todas as diferenças existentes, a política da diferença parte da discriminação para a partir disso criar um 
tratamento único para essas identidades. É através da política da diferença que grupos minoritários ganham espaço e voz, já que as suas diferenças serão destacadas a fim de um tratamento mais democrático diante da sociedade, uma vez que, segundo o autor, "se nos preocupamos com a identidade, o que é que há de mais legítimo do que o desejo de nunca a perdermos?” (TAYLOR, 1998, p.60, 61). Porém, as duas políticas se assemelham na percepção do respeito, tendo ele como um dos principais pilares em sua construção.

O grande problema da política de igual dignidade é o fato de ela ignorar as diferenças, quando na verdade deveria destacá-las. Quando existe um tratamento igualitário para todas as pessoas, esse tratamento deixa de ser igual, visto que não leva em consideração as especificidades de cada grupo, não atendendo as suas particularidades. O que resultaria em uma sociedade injusta e discriminatória, uma vez que a cultura hegemônica tende a ter essas características. Nas palavras do filósofo (TAYLOR, 1998, p.58-59):

Em relação à política de igual dignidade, aquilo que se estabelece visa a igualdade universal, um cabaz idêntico de direitos e imunidades; quanto à política de diferença, exige-se o reconhecimento da identidade única deste ou daquele indivíduo ou grupo, do carácter singular de cada um. Quer isto dizer, por outras palavras, que é precisamente esta singularidade que tem sido ignorada, disfarçada, assimilada a uma identidade dominante ou de maioria. E é esta assimilação que constitui o pecado cardeal contra o ideal de autenticidade. 
A política da diferença destaca que essa singularidade, que antes era ignorada por uma política universalista, hoje ganha importância e relevância com essa política. Com isso, a política da diferença estabelece a não-discriminação de uma cultura como uma exigência para a sua funcionalidade e ofereces direitos distintos aos indivíduos é o caminho para a igualdade, ressaltando sempre as suas peculiaridades.

Taylor (1998) traz o conceito de um potencial humano universal em que ele usa para contemplar a política da dignidade. Para ele, isso é a existência de uma capacidade igualitária a qualquer indivíduo de ser um humano, independentemente de suas atribuições e sua identidade. Entretanto, a política da diferença, mesmo que baseada na ideia de uma universalidade do humano, propõe um potencial a cada indivíduo para formar a sua própria identidade e essa potencialidade "deve ser igualmente respeitada em todas as pessoas" (TAYLOR, 1998, p.62). O autor afirma que o conflito existente entre a política da dignidade e a política da diferença é ter como base a noção de respeito igual, logo (TAYLOR, 1998, p.63):

Os dois tipos de política que se baseiam na noção de respeito igual entram em conflito. Em primeiro lugar, o princípio do respeito igual exige que as pessoas sejam tratadas de uma forma que ignore a diferença. A intuição fundamental de que este respeito depende das pessoas centra-se naquilo que é comum a todas elas. Em segundo lugar, temos de reconhecer e até mesmo encorajar a particularidade. A crítica que a primeira faz à segunda consiste na violação que esta comete do 
princípio de não-discriminação. Inversamente, a primeira é criticada pelo fato de negar a identidade, forçando as pessoas a ajustaram-se a um molde que não lhes é verdadeiro.

Com isso, Taylor critica a política de dignidade ao dizer que o respeito é o pilar de sua política. Essa forma de política, como imposição e adequação dos indivíduos a ela torna-se uma grande forma de opressão e violência às identidades únicas. O respeito é encontrado quando se é possível ser reconhecido por ser quem é, pela sua essência e seu potencial de ser humano. Pensar nas particularidades de grupos que precisam de reconhecimento e dos indivíduos que necessitam que as suas identidades sejam, de fato, reconhecidas, é caminhar para uma política de reconhecimento inclusiva.

Vale ressaltar que essa política da diferença está diretamente relacionada com a luta por reconhecimento. Elas são indissociáveis e essa política só se torna possível dentro de uma política de reconhecimento. Essa luta por reconhecimento de identidades não é algo definitivo que conquistamos e nunca mais se torna necessário. E também não é dado a alguém. O reconhecimento é uma constante luta por aqueles que receberam o não-reconhecimento, o desrespeito, e que buscam ser reconhecidos pelas suas identidades. A luta por reconhecimento é um conflito que deve ser constante e permanente.

\section{CONSIDERAÇÕES FINAIS}


O artigo propôs ressaltar a importância e a necessidade da luta por reconhecimento e do debate ético-político a respeito dos conceitos de identidade, autenticidade e reconhecimento. É necessário enfatizar que a teoria do reconhecimento, discutida por Taylor e Honneth é relacionada a um reconhecimento intersubjetivo. Por mais que Taylor aborde e relacione os seus conceitos a um ideal multicultural, a formação do self e a construção da identidade é atribuído a intersubjetividade e, sintetizar a luta por reconhecimento apenas a uma luta cultural é relativizar todo o seu processo.

Compreendendo a luta por reconhecimento como uma luta intersubjetiva, fica mais claro de entender que o seu processo não é algo tão simples, visto que "admitir que se trata de uma luta é assumir que o reconhecimento não pode ser concedido, alcançado ou doado... Ele não é um prêmio final que liberta grupos oprimidos." (MENDONÇA, 2009, p.147). A intersubjetividade se torna uma palavra-chave para a compreensão da luta por reconhecimento. A relação com o outro é algo indispensável para construir identidades e alcançar a autorrealização. O reconhecimento acontece na medida que me relaciono com o outro e, sempre, nas interfaces da igualdade e da diferença. Esse constante conflito faz parte dos problemas contemporâneos e nos leva a confirmação de que o reconhecimento não é dado, é conquistado. Mas também não é conquistado de uma forma definitiva. É uma incessante luta. Para além de um 
reconhecimento negado, as diferenças existentes nos indivíduos e nos grupos sociais são propulsoras dessa luta.

Aliado ao reconhecimento, a questão da autenticidade se faz necessária para que haja esse autoconhecimento de cada indivíduo. A autenticidade, vinculada com a questão da identidade, tem tomado um espaço importantíssimo dentro das discussões identitárias. É preciso, primeiramente, buscar o autoconhecimento para que os indivíduos possam se relacionar com os demais importantes a fim de que consigam construir suas próprias identidades. É a partir desse diálogo e do reconhecimento no outro que será possível essa construção.

Taylor ao propor uma política de reconhecimento na contemporaneidade só faz realçar a sua urgência em nossa sociedade. Torna-se então imprescindível o reconhecimento das diferenças em órgãos e instituições públicas, afim de que grupos culturais consigam receber os seus devidos direitos conformes as suas necessidades. Ao possibilitar o devido reconhecimento, que de acordo com Taylor, é uma necessidade vital (TAYLOR, 1998), é dada a oportunidade de indivíduos formarem e desenvolverem as suas identidades individuais.

Os dilemas entre a igualdade e diferença fazem com que haja uma necessidade de uma política que aborde sobre essa problemática. A política da diferença surge na tentativa de 
contemplar falhas originadas pela política universal, onde buscou apenas o reconhecimento de indivíduos semelhantes. A política da diferença traz à tona que as diferenças existentes entre os agentes sociais são determinantes para a política do reconhecimento. Por fim, é possível observar a contribuição de Taylor para este debate sobre a política do reconhecimento e como o autor consegue fazer uma reconfiguração política sobre as problemáticas da construção do self e a questão da autenticidade, conseguindo assim evidenciar que a questão do reconhecimento está longe de ser algo tão simples.

\section{Referências}

HONNETH, Axel. Luta por reconhecimento: a gramática moral dos conflitos sociais. São Paulo: Ed. 34, 2003.

MATTOS, Patrícia. A sociologia política do reconhecimento: as contribuições de Charles Taylor, Axel Honneth e Nancy Fraser. São Paulo: Annablume, 2006.

MENDONÇA, Ricardo F. Dimensão intersubjetiva da autorealização: Em defesa da teoria do reconhecimento. Revista Brasileira de Ciências Sociais - vol. 24 nº 70, 2009.

TAYLOR, Charles. A Ética da Autenticidade. Tradução Talyta Carvalho. São Paulo: É Realizações, 2011. 
TAYLOR, Charles. Hegel e a sociedade moderna. São Paulo: Edições Loyola, 2005.

TAYLOR, Charles. et al. Multiculturalismo: examinando a política de reconhecimento. Lisboa: Instituto Piaget, 1998.

Data de registro: 04/12/2020

Data de aceite: 10/04/2021 